\title{
Asymmetric mandible identification using cone beam computed tomography (CBCT)
}

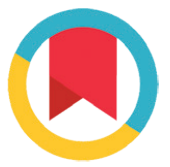

CrossMark

\author{
Barunawaty Yunus, Zulfikar R. Mailili, Dwi P. Wulansari*
}

Abstract

Objective: To determine the prevalence of patients with asymmetric mandible based on age, gender and severity that examined using CBCT section of the Dental and Oral Hospital of Hasanuddin University. Material and Methods: Secondary data from dental records (CBCT data) of patients at Dental and Maxillofacial Department in Dental and Oral Hospital of Hasanuddin University from January 2014-March 2016 were examined. The data collected to calculate the prevalence of

asymmetric mandible from $\mathrm{CBCT}$ image then presented in tabular form. Results: From this research it is found that the age group 36-50 years was the top ranked in prevalence of asymmetric mandible, and there is no significant difference between the number of male and female patients.

Conclusion: Asymmetric mandible caused by pathological factors have the highest incident.

Keywords: Asymmetric mandible, CBCT, Radiography

Cite this Article: Yunus B, Mailili ZR, Wulansari DP. 2019. Asymmectric mandible identification using cone beam computed tomography (CBCT). Journal of Dentomaxillofacial Science 4(1): 36-38. D01:10.15562/jdmfs.v4i1.666

Department of Dental Radiology, Faculty of Dentistry, Hasanuddin University, Makassar, Indonesia
"Correspondence to: Dwi P. Wulansari, Department of Dental Radiology, Faculty of Dentistry, Hasanuddin University, Makassar, Indonesia dwiputriwulansari51@gmail.com

Received: 20 July 2017 Revised: 3 February 2018 Accepted: 18 Desember 2018 Available Online 1 April 2019

\section{Introduction}

Asymmetry in the mandible disproportionality is an imbalance between the right and left sides of the mandible. Asymmetric mandible may be unilateral or bilateral, leading to the anteroposterior, superoinferior, and mediolateral. ${ }^{1-4}$

During times of symmetry, mandibular growth is affected by the condition of elongation hemimandibular and hemimandibular hyperplasia. Another factor that can affect the symmetry of the mandible are factors such as tumor pathology in the orofacial region, cysts, infections, and condylar resorption. Asymmetric mandible may occur also in patients with trauma injuries in the area orofasial. ${ }^{5}$

Asymmetry in the mandible can be seen from frontal view. However, inferior and superior views can not be ignored because it can show the length of asymmetry in relation to the entire face. If there is a mandibular asymmetry, it is important to check the co-existing slope of maxillary occlusal plane. Mandibular asymmetry will show the same mismatch center line in centric relation and centric occlusion. It should be noted that although the facial aesthetic also indicate the level of skeletal asymmetry with a slight tendency for dominant on the right side. Mandibular asymmetry seen in the growth of children between the age of 7 years and 16 years. It may not always be clinically important because it illustrates the inconsistency of normal growth in mandible bone. . $^{3-6}$

CBCT provides ideal image of the anatomical structures of high contrast and is especially useful for evaluating bone. For this reason, CBCT is rapidly replacing conventional CT and conventional radiography in clinical orthodontic practice. There are three categories of CBCT scanners: comprehensive view (FOV), FOV medium and small FOV scanner. Large-volume scanner is able to scan the facial bones as a whole, the volume is being used to scan both jaws together, while the small volume scanner is suitable for imaging a single jaw, facial bones smallest part and a small group of teeth. ${ }^{7-10}$

\section{Material and Methods}

This research is a descriptive research which is illustrating a systematic and accurate information on the facts include the nature and relationship between the phenomenon under study. This study was conducted on April-May 2016 at Department of Radiology Dental Hospital Hasanuddin University.

The study population was all the medical records of patients examined with $\mathrm{CBCT}$ at the Dental and Maxillofacial Department in Dental and Oral Hospital of Hasanuddin University from January 2014 to March 2016. The sampling method used in this study was a non-probability sampling with purposive sampling technique. The purposive sampling technique is a sampling technique to select a subject based on specific criteria that have been determined by researchers, such as: patients at the Dental and Maxillofacial Department in Dental and Oral Hospital of Hasanuddin University conducted CBCT examinations. From the calculation of the data, prevalence of asymmetric 
Table 1 Distribution asymmetrical mandible prevalence by age

\section{Abnormalities Mandible}

Age (year) Normal Asymmetric mandible Asymmetric mandible(P) Total

\begin{tabular}{lllll}
\hline $7-17$ & 6 & 0 & 3 & 9 \\
& $8.3 \%$ & $0.0 \%$ & $4.2 \%$ & $12.5 \%$ \\
$18-35$ & 22 & 1 & 6 & 29 \\
& $30.6 \%$ & $1.4 \%$ & $8.3 \%$ & $40.3 \%$ \\
$36-50$ & 12 & 2 & 9 & 23 \\
& $16.7 \%$ & $2.8 \%$ & $12.5 \%$ & $31.9 \%$ \\
$51-65$ & 8 & 0 & 1 & 9 \\
& $11.1 \%$ & $0.0 \%$ & $1.4 \%$ & $12.5 \%$ \\
$>66$ & 2 & 0 & 0 & 2 \\
& $2.8 \%$ & $0.0 \%$ & $0.0 \%$ & $2.8 \%$ \\
Total & 50 & 3 & 19 & 72 \\
& $69.4 \%$ & $4.2 \%$ & $26.4 \%$ & $100.0 \%$ \\
& & & & \\
\hline
\end{tabular}

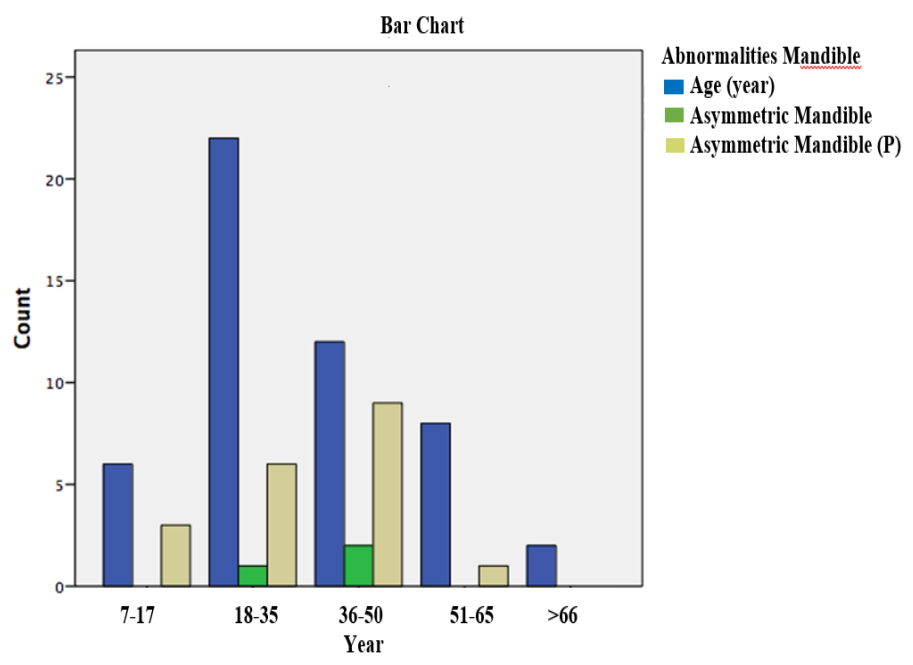

Figure 1 The bar chart of Mandible Asymmetrical distribution of the prevalence of patients by age

Table 2 The prevalence of asymmetric mandible by gender

\begin{tabular}{lllll}
\hline Gender & TAK & $\begin{array}{c}\text { Abnormalities Mandible } \\
\text { Asymmetric mandible }\end{array}$ & $\begin{array}{c}\text { Asymmetric mandible(P) } \\
\text { Astal }\end{array}$ & Total \\
\hline \multirow{2}{*}{ Male } & 16 & 2 & 7 & 25 \\
& $12.2 \%$ & $2.8 \%$ & $9.7 \%$ & $34.7 \%$ \\
Female & 34 & 1 & 12 & 47 \\
& $47.2 \%$ & $1.4 \%$ & $16.7 \%$ & $65.3 \%$ \\
Total & 50 & 3 & 19 & 72 \\
& $69.4 \%$ & $4.2 \%$ & $26.4 \%$ & $100.0 \%$
\end{tabular}

mandible in the Dental and Maxillofacial Department in Dental and Oral Hospital of Hasanuddin University was determined. Then discussed descriptively using tables.

\section{Results}

The CBCT data of 72 patients divided into group based on age and gender. Data taken during the period from April to May 2016. Overall medical records were obtained from the Dental Hospital at the Department of Maxillofacial Hasanuddin University.

From table 1 and figure 1 it can be seen that the number of people with asymmetrical mandible by age group 7 - 66 years is 3 patients, 19 patients with asymmetric mandible caused by pathology factors, and 50 patients did not suffered asymmetric mandible. In the age group of 7-17 years showed as much as $4.2 \%$, the age group $18-35$ years $9.7 \%$, the age group $36-50$ years $15.3 \%$, the age group 51-65 as much as $1.4 \%$.

From table 2 and figure 2 it can be seen the prevalence of asymmetric mandible is $2.8 \%$ men and $1.4 \%$ women, people with asymmetrical mandible caused by pathology is $9.7 \%$ men and $16.7 \%$ women, and patients who do not experience mandibular defects is $22.2 \%$ men and $47.2 \%$ women.

\section{Discussion}

This study found that the age group of 36-50 years was ranked at the top in the prevalence of asymmetric mandible with 2 asymmetric mandible patients $(2.8 \%)$ and 9 patients $(12.5 \%)$ of asymmetric mandibular caused by pathological factors. The prevalence of asymmetric mandible in male $12.5 \%$ and in women $18.1 \%$ and there was no significant difference between the number of male patients and female.

As a dentist it is important to consider a mandibular bone examination using $\mathrm{CBCT}$ techniques as an

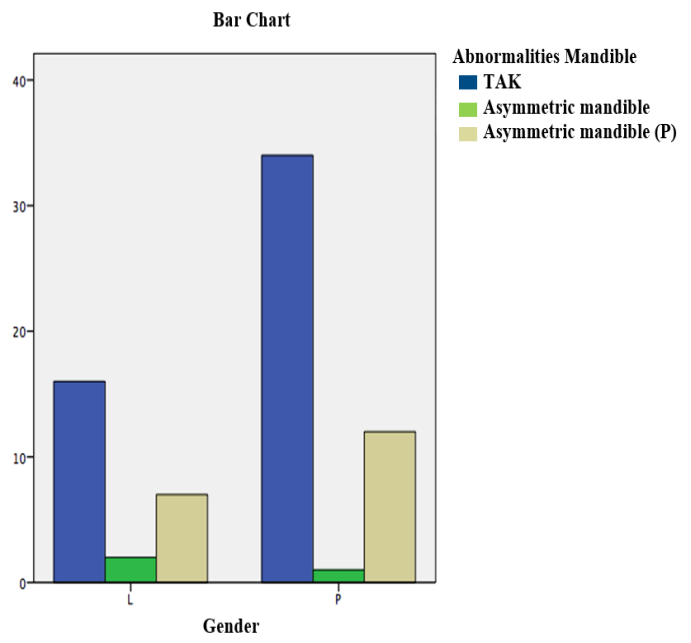

Figure 2 The bar chart Asymmetric mandibular prevalence by gender. 
additional examination to avoid errors in diagnosis. There are some obstacles during the research such as uncomplete contents of the medical record. It is the authors difficult in grouping abnormalities mandible. Information about the etiology in medical records is useful to determine the etiology of mandibular abnormalities that occur. It is necessary to complete the contents of the medical record. ${ }^{11-15}$

\section{Conclusion}

The type of abnormality with the highest incidence is the asymmetric mandibular caused by pathological factors. In contradiction, the asymmetric incidence of mandible caused by genetic factors is quite low.

\section{Aknowledgment}

We are very grateful for all parties involved in this research.

\section{Conflict of Interest}

The authors report no conflict of interest.

\section{References}

1. Miloro M. Peterson's principles of oral and maxillofacial surgery. 2nd ed. Hamilton: BC Decker; 2004.

2. Venkatesh E, Elluru SV. Cone beam computed tomography: basics and applications in dentistry. J Istanb Univ Fac Dent 2017;51: S102-S121.

3. Chia MS, Naini FB, Gill DS. The aetiology, diagnosis and management of mandibular asymmetry. Ortho update 2008;1: 44-52.
4. Kritzler K. CBCT imaging vs conventional radiography. Am J Orthod Dentofacial Orthop 2017;152: 146-148.

5. Epsilawati L. CBCT analysis in osteoradionecrosis case followed by hyperbaric oxygen treatment (a case study). J Dentomaxillofac Sci 2016;1: 67-72.

6. Kailash S. CBCT-Cone Beam Computed Tomography. J Dent Educ 2014;1: 9-15.

7. Ludlow JB, Ivanovic M. Comparative dosimetry of dental CBCT devices and 64-slice CT for oral and maxillofacial radiology. Oral Surg Oral Med Oral Pathol Oral Radiol Endod 2008;106: 106-114.

8. Cheong YW, Lo LJ. Facial asymmetry: etiology, evaluation, and management. Chang Gung Med J 2011;34: 341-351.

9. Allgayer S, Mezzomo FS, Polido WD, et al. Orthodontics-surgical treatment of skeletal facial asymmetry: case report. Dent press J orthod 2011;16: 100-110.

10. Yanez GOR, Stewart A, Franken E, et al. Prevalence of mandibular asymmetries in growing patients. Euro J Ortho 2011;33: 236-242.

11. Maheshwari S, Verma SK, Gaur A, et al. Diagnosis and management of facial asymmetries. J Ortho Res 2015;3.

12. Gribel BF, Thiesen G, Borges TS, Freitas MPM. Prevalence of mandibular asymmetry in skeletal class 1 adult patients. JRD-J Res Dentist Tubarao 2014;2.

13. Wahyuni A, Yunus M, Ruslin M. The difference uses of panoramic photo and cbct evaluation of the gnathoplasty surgery outcome. J Dentomaxillofac Sci 2017;2: 110-113.

14. Yunus B, Amalia R. Detecting osteoporosis in elderly women with panoramic radiography technique. J Dentomaxillofac Sci 2016;1: 155-157.

15. Vico RMY, Linares AI, Lagares DT, et al. Diagnostic of craniofacial asymmetry. Literarure review. Med Oral Patol Oral Cir Bucal 2010;15: e494-e498.

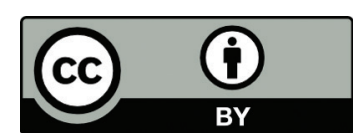

This work is licensed under a Creative Commons Attribution 